\title{
Tomato Chlorosis Virus: A New Whitefly-Transmitted, Phloem-Limited, Bipartite Closterovirus of Tomato
}

\author{
G. C. Wisler, R. H. Li, H.-Y. Liu, D. S. Lowry, and J. E. Duffus
}

USDA-ARS Crop Improvement and Protection Research Unit, 1636 E. Alisal Street, Salinas, CA 93905.

Accepted for publication 22 January 1998.

\begin{abstract}
Wisler, G. C., Li, R. H., Liu, H.-Y., Lowry, D. S., and Duffus, J. E. 1998. Tomato chlorosis virus: A new whitefly-transmitted, phloem-limited, bipartite closterovirus of tomato. Phytopathology 88:402-409.

Tomato chlorosis virus (ToCV) is the second whitefly-transmitted, phloem-limited, bipartite closterovirus described infecting tomato. ToCV is distinct from tomato infectious chlorosis virus (TICV), based on lack of serological and nucleic acid cross-reactions and differences in vector specificity. TICV is transmitted only by the greenhouse whitefly (Trialeurodes vaporariorum), whereas ToCV is transmitted by the greenhouse whitefly, the banded-wing whitefly (T. abutilonea), and Bemisia tabaci biotypes A and B (B. argentifolii). Double-stranded (ds) RNA analyses of ToCV

several small dsRNAs. Digoxigenin-11-UTP-labeled riboprobes derived from cDNA clones representing portions of RNAs 1 and 2 were used in Northern blot hybridizations to detect two large nonhomologous dsRNAs and a subset of smaller dsRNAs. These probes were used in dot blot hybridizations to detect ToCV in infected tomato. Inclusion bodies and cytoplasmic vesicles were consistently observed in phloem tissues of ToCV-infected Nicotiana clevelandii. Computer-assisted sequence analysis showed significant homology between ToCV clones that hybridize specifically with RNAs 1 and 2 and the lettuce infectious yellows virus methyltransferase of RNA 1 and the HSP70 heat shock protein homolog of RNA 2, respectively. Thus, ToCV is another member of the growing subgroup of bipartite closteroviruses transmitted by whiteflies.
\end{abstract} show two prominent dsRNAs of approximately 7,800 and 8,200 bp, with
Tomato plants showing symptoms similar to those of the previously described whitefly-transmitted tomato infectious chlorosis virus (TICV) were submitted by R. C. Hochmuth and G. W. Simone of the University of Florida Plant Disease Clinic early in 1996 for whitefly transmission studies. A problem of greenhouse-grown tomatoes in north-central Florida since 1989, the cause of "yellow leaf disorder" had been attributed to physiological or nutritional disorders, pesticide phytotoxicity, or a virus (39). Symptoms of the yellow leaf disorder include irregular chlorotic mottling that develops first on lower leaves and gradually advancing toward the growing point. Interveinal yellow areas on leaves develop red or brown necrotic flecks. No obvious symptoms are produced on fruit or flowers. Significant yield reduction occurs due to a loss of photosynthetic area. Previous light and electron microscopic examinations, serological analyses, and mechanical inoculations to detect a virus infecting these symptomatic tomatoes were negative.

Whitefly-transmission experiments from symptomatic tomato samples submitted from Florida revealed that, unlike TICV, which is transmitted only by the greenhouse whitefly (Trialeurodes vaporariorum (Westwood)), the newly discovered virus causing the yellow leaf disorder of tomato is transmitted by the greenhouse whitefly Bemisia tabaci (Gennadius) biotypes A and B (by isozyme analysis) $(6,33)$ or $B$. argentifolii $(4)$ and the banded-wing whitefly ( $T$. abutilonea (Haldeman)) $(18,39,44)$. Although TICV has been found in both greenhouse- and field-grown tomatoes in California, North Carolina, and Italy, the new virus, termed tomato chlorosis virus (ToCV), has to date been identified from greenhouse-grown tomatoes in Baker, Columbia, Marion, and Suwanee Counties in Florida, and in Colorado and Louisiana. Symptoms of

Corresponding author: G. C. Wisler; E-mail address: gwisler@asrr.arsusda.gov

Publication no. P-1998-0319-01R

This article is in the public domain and not copyrightable. It may be freely reprinted with customary crediting of the source. The American Phytopathological Society, 1998.
TICV and ToCV cannot be easily distinguished in infected tomato, but differences are seen on the two indicator plants, Nicotiana benthamiana and $N$. clevelandii A. Gray. Whereas both species show interveinal yellowing when infected with either virus, only TICV causes necrotic flecking on these hosts (J. E. Duffus, unpublished data). All initial samples submitted from Florida were negative in dot blot hybridization experiments using TICV riboprobes and in Western blot analyses using TICV antisera, and no mechanically transmissible viruses were detected. ToCV isolates were maintained in insect-proof cages using $B$. tabaci to transmit.

This study describes ToCV of tomatoes, which is whitefly-transmitted, has a divided genome consisting of two single-stranded (ss) RNAs, produces phloem-limited virus inclusion bodies, and belongs to the new genus Crinivirus in the family Closteroviridae (G. P. Martelli, personal communication). The flexuous, filamentous particle morphology with distinct cross-banding seen with ToCV (45; H.-Y. Liu, unpublished data) is also typical of members of the family Closteroviridae. Cloned cDNAs were made from doublestranded (ds) RNAs from ToCV-infected plants, and probes specific to RNA 1 and RNA 2 were produced using digoxigenin-11-UTPlabeled (DIG-labeled) transcripts. These probes were used to determine the bipartite nature of ToCV, show that ToCV is distinct from TICV, and detect ToCV in infected tomato tissue and other selected host plants. Partial sequence analysis indicates the presence of an HSP70 encoding homolog in the ToCV cDNA clones analyzed, another indication that ToCV should be included as a new member of the genus Crinivirus.

\section{MATERIALS AND METHODS}

Light and electron microscopy. Leaf tissue samples prepared for transmission electron microscopy were obtained from greenhouse-grown specimens of $N$. clevelandii. Plants were infected with ToCV via the whitefly vector $B$. tabaci during a 48-h inoculation access period. Other plants destined for use as healthy controls were exposed to noninfective, virus-free whiteflies under iden- 
tical conditions. Segments of midvein were excised from leaves taken between 3 days and 35 days post-whitefly access and cut into pieces 1 to $2 \mathrm{~mm}$ in length. Samples were fixed for $2 \mathrm{~h}$ on ice with a $3 \%$ formaldehyde/3\% glutaraldehyde solution in $50 \mathrm{mM}$ phosphate buffer, $\mathrm{pH} 6.8$, and postfixed for $2 \mathrm{~h}$ on ice with a $1 \%$ osmium tetroxide solution in the same buffer. Samples were then treated for $2 \mathrm{~h}$ with an aqueous $0.25 \%$ uranyl acetate solution, dehydrated through a series of acetone washes, and gradually infiltrated with an Epon-Araldite resin mixture under continual rotation for a period of 2 to 3 days. Resin blocks were polymerized for $48 \mathrm{~h}$ at $60^{\circ} \mathrm{C}$. Thin sections were cut with a diamond knife on a MT-6000 ultramicrotome (RMC Inc., Tucson, AZ), collected on slotted copper grids, and allowed to dry on Formvar film. Sections were poststained with $1 \%$ uranyl acetate in $50 \%$ ethanol for 5 to 6 min, followed by lead citrate (37) for 3 to $4 \mathrm{~min}$. Images were generated and recorded with an EM 109 transmission electron microscope (Carl Zeiss Inc., Thornwood, NY).

For light microscopy, sections were cut by hand through the vascular tissues of the crown from ToCV-infected and noninoculated N. clevelandii. Tissues were stained with $0.1 \%$ azure A according to Christie and Edwardson (8) for $15 \mathrm{~s}$ in a microwave oven $(1,400 \mathrm{~W})$ at the maximum energy level (22). Leaf strips were then destained for 3 to 5 min with several changes of anhydrous ethanol and placed in Euparol mountant (Asco Laboratories, Manchester, England) on a polished glass slide. Observations were made on a Standard 16 microscope (Carl Zeiss Inc., Oberkochen, Germany) and images were recorded on T-Max 100 film (Eastman Kodak Co., Rochester, NY). Film was processed in Kodak T-Max developer (Eastman Kodak Co.) according to the manufacturer's specifications.

dsRNA isolation and cDNA cloning. ToCV was routinely propagated in $N$. clevelandii plants inoculated with B. tabaci biotype A as previously described, as well as by $T$. vaporariorum, T. abutilonea, and B. tabaci biotype B (15). dsRNAs were prepared according to Valverde et al. (42) using $7 \mathrm{~g}$ of tissue for each isolate and were analyzed in a $1 \%$ agarose gel made in Loen's buffer $(\mathrm{pH}$ 7.8) containing $0.07 \mathrm{M}$ Trizma base, $0.07 \mathrm{M} \mathrm{NaH}_{2} \mathrm{PO}_{4}$, and $0.2 \mathrm{mM}$ EDTA. A total of eight dsRNA preparations were combined and used as a template for cDNA cloning. The combined dsRNA preparations were extracted from a gel using the RNaid kit (Bio 101, Inc., Vista, CA) according to the manufacturer's instructions.

Approximately $1 \mu \mathrm{g}$ of gel-purified dsRNA was used for firststrand synthesis. The dsRNA was denatured in $20 \mathrm{mM}$ methylmercuric hydroxide, and the first- and second-strand cDNA was synthesized in accordance with standard procedures (38) using random hexamers and $40 \mathrm{U}$ of RNasin (Promega Corp., Madison, WI) for the first-strand cDNA. Products from the second-strand synthesis were treated with the Klenow fragment of DNA polymerase I and T4 polynucleotide kinase (United States Biochemical Corp., Cleveland) and were blunt end-ligated into SmaI-cut, dephosphorylated pBluescript SK(+) (Stratagene Inc., La Jolla, CA). The ligated products were transformed into competent ElectroMAX DH5 $\alpha$ cells using the Cell-Porator Escherichia coli Electroporation System (BRL, Grand Island, NY). White colonies were selected and recombinant plasmids were prepared according to the boiling method of Holmes and Quigley (24).

Nucleotide sequence analyses. Cloned cDNAs were increased according to Lee and Rasheed (31) and sequenced in both directions in recombinant plasmids at the University of Florida Interdisciplinary Center for Biotechnology Research (ICBR) DNA Sequencing Core Laboratory (Gainesville, FL) using universal T3 and T7 primers and virus-specific primers prepared by the ICBR DNA Synthesis Core Laboratory. Nucleotide and deduced amino acid sequence analyses were compared using the Pileup and Clustal programs of the University of Wisconsin Genetics Computer Group software package (11).

Putative translation products were compared with the GenBank nonredundant sequence database using the BLAST pro$\operatorname{gram}(2,3)$.
Northern and dot blot hybridization analysis. Plasmids were analyzed on a $1 \%$ agarose gel, and those ranging in size from approximately 0.8 to $2.5 \mathrm{kbp}$ were used to generate DIG-labeled RNA transcripts using the DIG-Labeling and Detection Kit (Boehringer Mannheim Biochemicals, Indianapolis, IN). Clones were first linearized with either EcoRI or PstI digestion, and then transcribed using T3 RNA polymerase.

After analysis of ToCV dsRNAs by staining with ethidium bromide $(0.5 \mu \mathrm{g} / \mathrm{ml})$, dsRNA was denatured by soaking the agarose gels in $50 \mathrm{mM} \mathrm{NaOH}$ for $10 \mathrm{~min}$, followed by neutralization in $20 \times \mathrm{SSC}(1 \times \mathrm{SSC}$ is $0.15 \mathrm{M} \mathrm{NaCl}$ plus $0.015 \mathrm{M}$ sodium citrate, $\mathrm{pH}$ 7.0) for $20 \mathrm{~min}$. The dsRNA was transferred overnight from gels to positively charged Hybond $\mathrm{N}+$ nylon membranes (Amersham Corp., Arlington Heights, IL) using an Optiblot Transfer Unit (Scotlab, Shelton, CT). Membranes were washed for $1 \mathrm{~min}$ in $2 \times$ $\mathrm{SSC}$, and dsRNA was fixed on the membranes by treatment with $0.05 \mathrm{~N} \mathrm{NaOH}$ for $5 \mathrm{~min}$, followed by another brief wash in $2 \times \mathrm{SSC}$. Hybridizations with ToCV-specific riboprobes were done at $55^{\circ} \mathrm{C}$ overnight. Washes, incubation with anti-DIG alkaline phosphatase, and development with the chemiluminescent substrate CSPD (Tropix Inc., Bedford, MA) were performed according to the manufacturer's instructions (Boehringer Mannheim Biochemicals).

Total RNA was extracted from whitefly-inoculated and noninoculated tomato, N. clevelandii, and Physalis wrightii tissues for dot blot analyses as previously described $(19,46)$. Five microliters of the total RNA extract was applied to Hybond N+ nylon membranes, which were then fixed and hybridized as described above. Chemiluminescence was detected on X-ray film.

Serology. The Western blotting procedure was conducted essentially according to the method of Towbin et al. (41) using a Bio-Rad Mini-PROTEAN II electrophoresis cell and Trans-Blot electrophoretic transfer cell (Bio-Rad Laboratories, Hercules, CA). Indirect enzyme-linked immunosorbent assay (ELISA) tests were conducted as described by Halk (20). Antisera to TICV were prepared as described by Duffus et al. (15-17) for lettuce infectious yellows virus (LIYV) and lettuce chlorosis virus (LCV). Antiserum to ToCV has not yet been prepared, because of the extremely low yields of ToCV in purified preparations.

\section{RESULTS}

Light and electron microscopy. Phloem tissues of ToCV-infected $N$. clevelandii plants stained with azure A contained cytoplasmic, red-violet inclusion bodies commonly observed in plants infected with other closteroviruses (Fig. 1A) (8). Inclusions were similar to those observed for TICV (46) and were often seen as fibrous aggregates that appeared as vacuolate bodies in phloem cells. Large pluglike inclusion bodies that stained violet were also observed in phloem cells of infected plants (Fig. 1B). Phloem tissues from healthy plants did not stain with azure A.

Ultrastructural observations revealed an accumulation of cytoplasmic vesicles in phloem tissue (Fig. 1C) similar to that reported for other closterovirus infections (23). Vesicles were initially seen in samples collected at 8 days postinoculation and appeared to be restricted exclusively to phloem companion cells. Virus particles were frequently associated with vesicles (Fig. 1C). Many vesicles contained reticulate arrangements of intersecting fibrils (Fig. 1C, inset) as previously described (23). In later stages of infection, degeneration of the cytoplasm and organelles was observed in companion cells and phloem parenchyma cells with viral particles aggregated into large bundles (Fig. 1D). Plasmalemma deposits as reported for LIYV (36) were not observed.

dsRNA analysis and cDNA cloning. dsRNA was chosen as the template for cDNA synthesis instead of virion RNA because of extremely low yields in repeated attempts to purify ToCV. Two prominent large dsRNAs were consistently purified from ToCVinfected $N$. clevelandii regardless of which vector was used (Fig. 2). These dsRNAs were estimated to be approximately 8.2 and $7.8 \mathrm{kbp}$, 

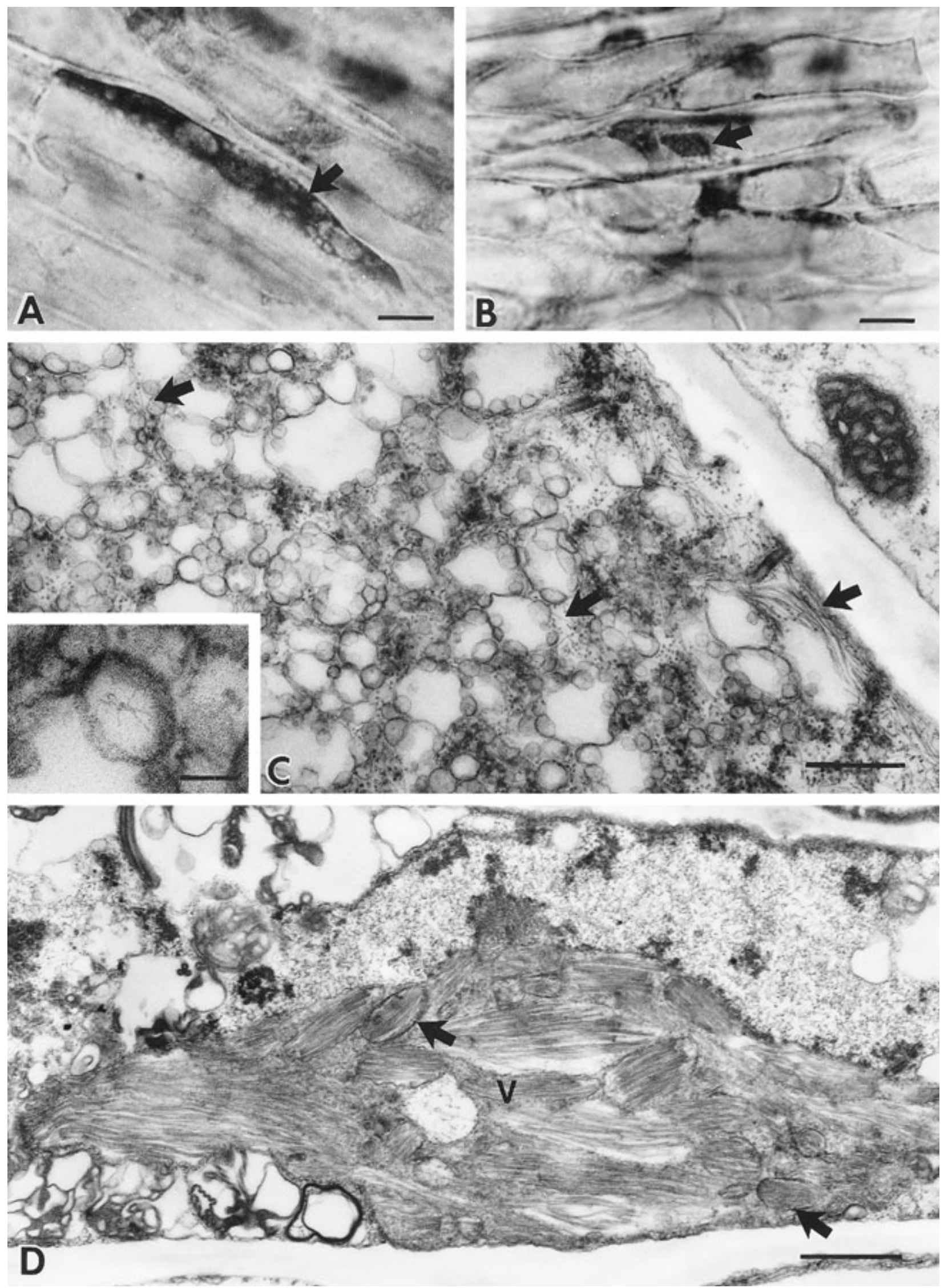

Fig. 1. Light and electron microscopic analysis of tomato chlorosis virus-infected Nicotiana clevelandii tissue. A and B, Freehand sections through vascular tissues were stained with azure A and photographed with a Zeiss standard microscope. Arrows indicate A, vacuolate and B, pluglike viral inclusion bodies in phloem tissue (bars $=10 \mu \mathrm{m})$. C , Cytoplasmic vesicles in a phloem companion cell sampled at 14 days postinoculation. Virus particles (arrows) are interspersed with vesicles $(\mathrm{bar}=0.5 \mu \mathrm{m})$. Many vesicles contain a reticulate arrangement of fine fibrils (inset; bar $=75 \mathrm{~nm}$ ). D, Phloem companion cell sampled at 24 days postinoculation. A large aggregate of virus particles $(\mathrm{V})$ is observed in the cytoplasm. Note various orientations of particles in discrete organized bundles within the large aggregate. Groups of particles appear to be surrounded by membranes (arrows). Cellular contents exhibit extreme degradation $($ bar $=1 \mu \mathrm{m})$. 
based on relative mobilities of the dsRNAs of TICV-infected $N$. clevelandii, which have previously been established at 7.4 and 7.8 $\mathrm{kbp}$ (46). The estimated sizes of the ToCV dsRNAs were only slightly larger than those of TICV dsRNAs.

cDNA clones with inserts ranging from approximately 800 to $2,500 \mathrm{bp}$ were used to produce DIG-labeled riboprobes and to screen for virus-specific sequences by dot blot hybridization analysis using dsRNA and total nucleic acid extracts from ToCV-infected and healthy $N$. clevelandii plants. Those clones that reacted with dsRNA and total nucleic acid extracts from ToCV-infected tissue were increased and purified for nucleotide sequence analyses.

Specificity of ToCV cDNA clones. The ToCV-specific clones, which by comparison with LIYV sequence (29) correspond to areas within the methyltransferase coding region of LIYV RNA 1 and the HSP70 coding region of RNA 2 were used in Northern blot assays to confirm the bipartite nature of the ToCV genome (Fig. 3). The clone designated as pToC 11 , representing the $5^{\prime}$ end of RNA 1 (corresponding to LIYV RNA 1 at nucleotide positions 451 to 1,250) (Fig. 4), hybridized with the approximately 8.2-kbp dsRNA seen in ethidium bromide-stained gels. The clone designated as pToC8, representing the HSP70 coding region (corresponding to LIYV RNA 2 at positions 1,377 to 2,496), hybridized with the bottom prominent dsRNA at approximately $7.8 \mathrm{kbp}$ and with several smaller dsRNAs, some of which correspond to those observed in ethidium bromide-stained gels. Like results observed for TICV, the results from Northern blot hybridization analyses using cRNA

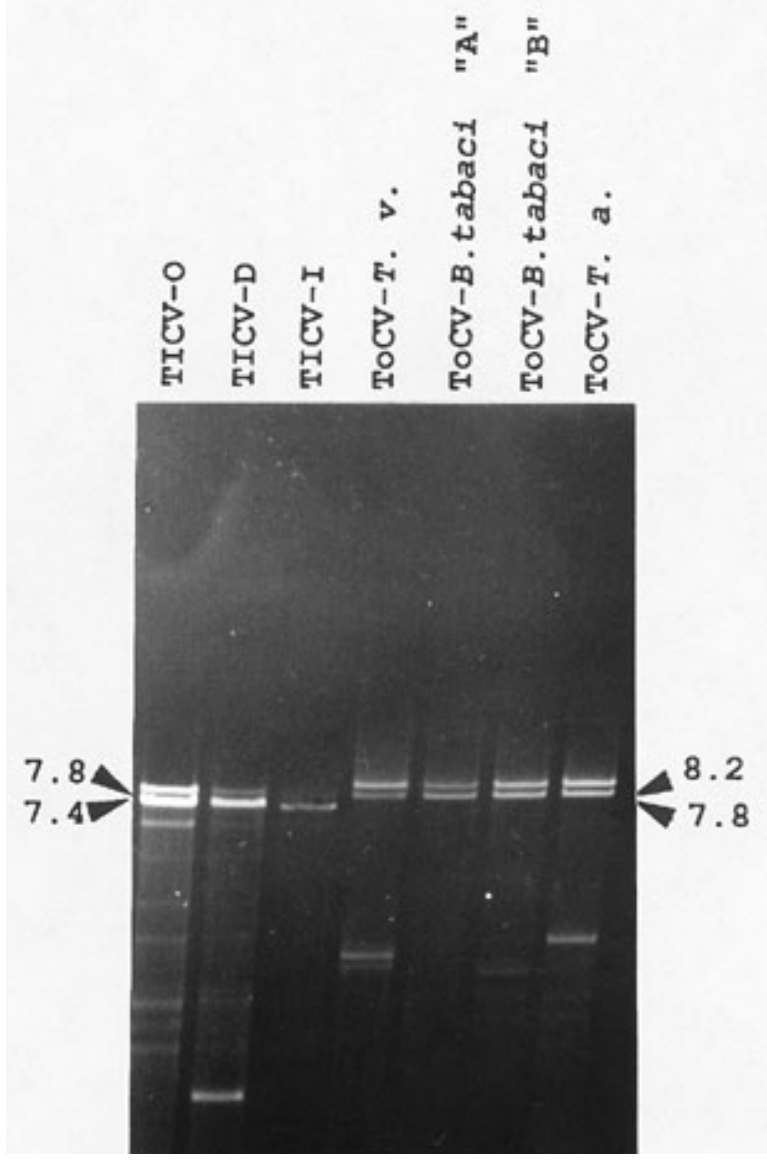

Fig. 2. Ethidium bromide-stained $1.0 \%$ agarose gel of tomato infectious chlorosis virus (TICV) and tomato chlorosis virus (ToCV) double-stranded (ds) RNAs. Isolates of TICV are from Orange County, CA (TICV-O); Davis, CA (TICV-D); and Italy (TICV-I). Isolates of ToCV represent separate transmissions each from individual whitefly species. These include Trialeurodes vaporariorum (T. v.), Bemisia tabaci biotype A, B. tabaci biotype B, and T. abutilonea. (T. a.). Relative sizes of TICV and ToCV, based on their migration, are indicated by arrows. Relative sizes of dsRNAs are based on those of TICV that have been previously established (46). probes representing regions of ToCV RNA 1 and RNA 2 confirm the presence of two groups of nonhomologous dsRNAs.

When tested in reciprocal dot blot hybridization analyses, ToCV probes representing RNA 1 and RNA 2 hybridized only with ToCVinfected plant extracts from tomato and ToCV dsRNA (Fig. 5). No reactions were observed with healthy tomato extracts or with extracts from plants infected with LIYV, LCV, cucurbit yellow stunting disorder virus (CYSDV) (data not shown), or TICV. Riboprobes representing TICV RNA 1 and RNA 2 did not hybridize with ToCV-infected plant extracts, ToCV dsRNA, or healthy plant extracts, but did hybridize with homologous TICV-infected plant extracts and TICV dsRNA as previously demonstrated $(32,44,46)$.

Sequence analyses. The sequence of clones used in hybridization studies were compared with those of other closteroviruses in the GenBank nonredundant sequence database. Sequences reported for the HSP70 gene were derived from clones that were either sequenced in both directions or confirmed by overlapping clones. The sequence of overlapping clones, designated as pToC8, pToC12, and pToC14 were assembled to determine the complete sequence of the HSP70 coding region (Fig. 4). The complete nucleotide sequence of the HSP70 coding region has been deposited in the GenBank database under accession number AF024630 and is not duplicated here. The ToCV HSP70 coding region consists of 554 amino acids with an estimated molecular weight of 61,950 . The phosphate 1 and phosphate 2 and the connect 1 and 2 motifs (5) are conserved when compared with the HSP70 from other closteroviruses according to their amino acid sequences. However, the degenerate primers designed from HSP70 consensus sequences to amplify whitefly closteroviruses by reverse transcriptase-polymerase chain reaction (RT-PCR) (40) did not amplify ToCV in repeated attempts using several annealing temperatures and $\mathrm{Mg}^{+}$

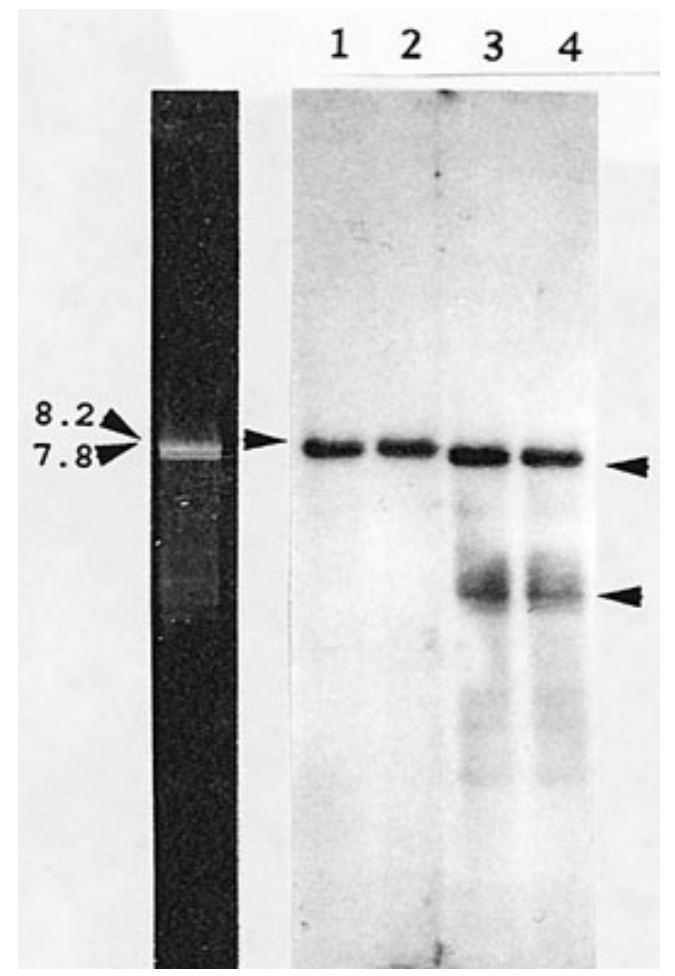

Fig. 3. Ethidium bromide-stained 1.0\% agarose gel (left panel) and corresponding Northern blot hybridization (right panel) analysis of tomato chlorosis virus (ToCV) double-stranded (ds) RNAs. Electrophoresis was for $5 \mathrm{~h}$ at 50 V. Hybridization experiments show two prominent ToCV dsRNAs with several smaller ones, some of which correspond to those seen in ethidium bromide-stained gels. Arrows to the left of the ethidium bromide-stained gel indicate the upper two large dsRNAs. Northern blot hybridization analysis of replicate dsRNA samples probed with lanes 1 and 2, pToC11 (RNA 1); and lanes 3 and 4, pToC8 (RNA 2). Arrows at the left of the Northern blot indicate RNA 1 and to the right indicate RNA 2 and one of the small dsRNAs. 
concentrations. In the same experiments, TICV was used as a positive control and was consistently amplified. The reason for this became clear when the nucleotide sequence of ToCV was compared with those of other whitefly-transmitted closteroviruses (Fig. 6). Differences exist at two nondegenerate positions in the HSP-P-1 primer (positive polarity primer) and at one position in the HSP-P-2 primer (complementary to the virus nucleotide sequence). The single difference in the HSP-P-2 primer may be the most important in terms of limiting the success of the RT-PCR reaction, because it is the primer used in the initial RT step.

Additional clones that have been sequenced or used in Northern and dot blot hybridizations represent part of the helicase domain (open reading frame [ORF] 1a; pToC76 and pToC85); the junction between ORFs $1 \mathrm{a}$ and $1 \mathrm{~b}$, which includes the +1 ribosomal frameshift region (pToC66); the $3^{\prime}$ portion of ORF 3 on RNA 2 (pToC6); the coat protein $(\mathrm{CP})$; and the diverged duplicate of the $\mathrm{CP}$ (pToC78 and pToC86) (Fig. 4). In all comparisons, a high similarity was found with LIYV, with BLAST scores over 100. The highest similarity was with the clone designated as pToC66, of approximately $1 \mathrm{kbp}$, which corresponds to the junction between ORFs $1 \mathrm{a}$ and $1 \mathrm{~b}$ (Fig. 7) with a $69 \%$ amino acid similarity to LIYV. Sequences corresponding to the CP of ToCV had a BLAST score of 420 and an amino acid similarity of $55 \%$ when compared with that of sweet potato sunken vein virus (SPSVV) (25). The diverged duplicate of the ToCV CP $(\mathrm{CPd})$ is larger than that reported for LIYV, with 669 amino acids and an estimated molecular weight of $75 \mathrm{kDa}$. This larger size of the ToCV CPd is similar to that of SPSVV, which is reported to be $79 \mathrm{kDa}(25)$, whereas that of LIYV is 59 $\mathrm{kDa}(29,30)$. Like that of LIYV and SPSVV, the ToCV CPd is located downstream from the CP. In contrast, the CPd of the monopartite closteroviruses that have been sequenced are significantly smaller, at $27 \mathrm{kDa}$ for citrus tristeza virus (CTV) (27), $25 \mathrm{kDa}$ for beet yellow stunt virus (BYSV) (28), and $24 \mathrm{kDa}$ for beet yellows virus (BYV) $(1,28)$, and are located upstream from the CP.

Serology. Indirect ELISA tests with TICV- and ToCV-infected tissue extracts against TICV antisera revealed homologous positive reactions with TICV-infected $N$. clevelandii tissues. Reactions using ToCV-infected tissues resulted in only slightly elevated readings above those of healthy tissue. For example, the average absorbance at $405 \mathrm{~nm}\left(A_{405}\right)$ values for two wells for TICV-infected tissue samples ranged from 0.50 to 1.18 . The average $A_{405}$ values for ToCV-infected tissues ranged from 0.05 to 0.10 , and the average $A_{405}$ values for healthy $N$. clevelandii samples were 0.009 . By comparison, when TICV antiserum was tested against tissue extracts

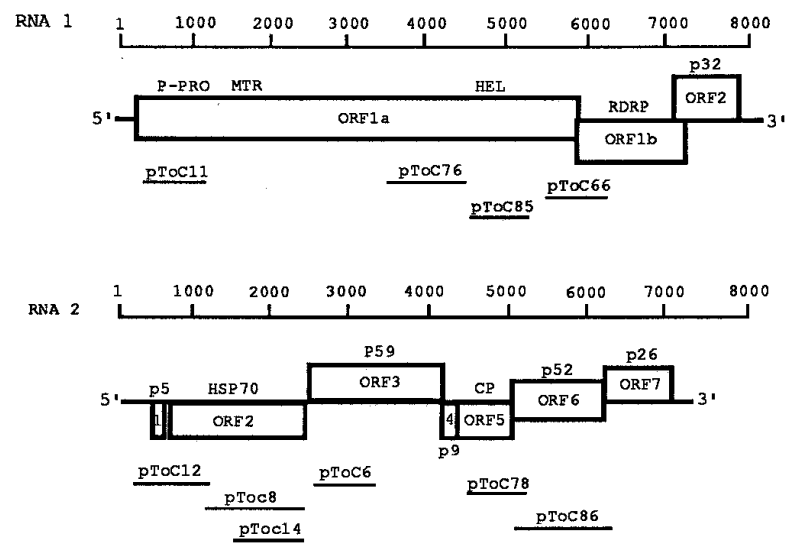

Fig. 4. Diagram showing the tomato chlorosis virus cloning strategy and alignment of clones that correspond to the genome of lettuce infectious yellows virus (LIYV) as shown by Klaassen et al. (30). A scale bar with nucleotide numbers ( $5^{\prime}$ to $3^{\prime}$ ) is shown above the genome map of RNA 1 (top) and RNA 2 (bottom) of LIYV. Horizontal lines below each LIYV RNA represent corresponding cDNA clones with their respective designations used to determine the nucleotide sequence or for Northern and dot blot hybridizations. from plants infected with other closteroviruses including LIYV, LCV, BYV, and CYSDV, the average $A_{405}$ values were comparable to the healthy tissue readings.

Homologous TICV reactions in Western blot analyses reveal a characteristic band at approximately $32 \mathrm{kDa}$ for TICV-infected plant extracts and for purified TICV virions (32). Detectable reactions were not routinely observed using ToCV-infected plant extracts against TICV antiserum. Some ToCV-infected hosts in which a particularly high virus concentration was observed produced an extremely faint reaction with TICV antisera at approximately $32 \mathrm{kDa}$. For example, whereas ToCV-infected $N$. clevelandii extracts produced a faint band in Western blots, ToCV-infected tomato extracts did not. Contamination or mixed infection of these samples with TICV was ruled out by specificity of dot blot hybridizations and specific transmission by $B$. tabaci biotype B from test plants. The higher titer of TICV and ToCV in $N$. clevelandii as well as $P$. wrightii compared with tomato was evidenced by a far greater number of particles observed in routine leaf dips, higher virus yields in purification attempts, increased intensity of reactions in dot blot hybridizations and Western blots (TICV only), and the increased presence of virus-induced inclusion bodies seen with the light microscope.

\section{DISCUSSION}

The new Crinivirus genus of whitefly-transmitted, bipartite closteroviruses continues to grow. LIYV is the type member of this new genus, and TICV was the first of this group to be described infecting tomato. However, a second member of this genus, ToCV, has now been described in tomato, and although it has many similarities to TICV, it is a distinct virus. The characteristics of the genus Crinivirus that are common to both TICV and ToCV are (i) a characteristic particle length of between 800 to $850 \mathrm{~nm}$ $(16,17,45$; H.-Y. Liu, unpublished data), (ii) limitation of virions

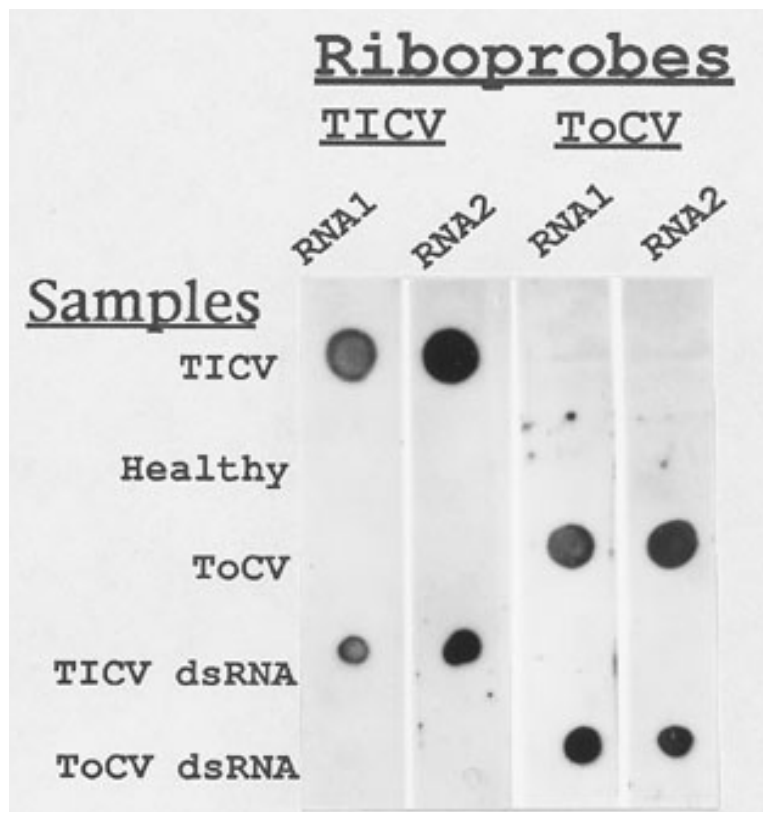

Fig. 5. Reciprocal dot blot hybridization analysis using digoxigenin-11UTP-labeled RNA transcripts that represent portions of RNA 1 and RNA 2 from tomato infectious chlorosis virus (TICV) and tomato chlorosis virus (ToCV). Samples ( $5 \mu \mathrm{l}$ of tissue extracts, $1 \mu \mathrm{l}$ of dsRNA) are, from top to bottom, total nucleic acid extracts from TICV-infected tomato, healthy tomato, ToCV-infected tomato, TICV dsRNA, and ToCV dsRNA. TICV clones pSPT7-46 and pSPT4-26 correspond to 950 bp from the $3^{\prime}$ terminus of RNA 1 and $966 \mathrm{bp}$ at the junction of the coat protein and the diverged duplicate coat protein of RNA 2, respectively. Clones pToC8 and pToC11 represent portions of the methyltransferase coding region of RNA 1 and the HSP70 coding region of RNA 2 of the ToCV genome, respectively. 
and inclusion bodies to the phloem tissue, (iii) cytoplasmic vesicle formation, (iv) encapsidation of two nonhomologous RNAs, and (v) sequence similarities of the HSP70 protein-encoding gene to those of established closteroviruses including LIYV, CYSDV, CTV, and BYV.

An important difference between TICV and ToCV is that of vector specificity. Whereas TICV is only transmitted by the greenhouse whitefly (17), ToCV is transmitted by four different whiteflies $(18,44)$. Although both TICV and ToCV have wide host ranges, only TICV infects lettuce (J. E. Duffus, unpublished data). These factors could greatly influence the epidemiology of these viruses.

TICV and ToCV were also shown to be distinct viruses based on the lack of cross-hybridization using clones representing RNA 1 and RNA 2 in reciprocal Northern and dot blot hybridizations. This lack of cross-reactivity between TICV and ToCV was demonstrated with plant tissue extracts and dsRNA preparations. The size of the two dsRNAs from TICV and ToCV were also different, with the dsRNAs from all three isolates of TICV migrating slightly faster $(7.4$ and $7.8 \mathrm{kbp})$ than those from each of four isolates of ToCV (7.8 and $8.2 \mathrm{kbp}$ ) derived from four different vector species transmissions. TICV antiserum reacted weakly in Western blot analyses only against ToCV-infected hosts that have typically higher titers than tomato ( $N$. clevelandii and $P$. wrightii). Similarly, in indirect ELISA tests, TICV antiserum repeatedly produced absorbance readings that were slightly elevated when tested against ToCV-infected tissues. Although ELISA readings were elevated above those for healthy tissue and other nonhomologous closteroviruses, these readings were not considered to be positive.
TICV and ToCV infections in tomato are difficult to distinguish based on symptomatology alone, although symptoms of ToCV may be slightly less severe than those of TICV in some tomato cultivars and indicator plants tested. Interestingly, the HSP70-specific primers designed to detect bipartite closteroviruses (40) did not amplify ToCV in repeated tests, whereas TICV was consistently amplified. Partial sequence analysis revealed that the upstream degenerate primer was different from the ToCV sequence in two locations that were not degenerate, and the downstream primer had a difference in the third nondegenerate nucleotide from the $3^{\prime}$ end. However, the use of riboprobes specific for RNAs of both TICV and ToCV, of antiserum specific to TICV, and of differential transmission by whitefly vectors can provide a conclusive diagnosis. The possibility exists for the existence of additional closteroviruses of tomato and other hosts that also may not amplify with the degenerate primers, so the use of several different types of diagnostic tests is highly recommended. Transmission studies by whiteflies are particularly important in hosts such as tomato in which both TICV and ToCV are restricted to phloem tissues and may exist in very low concentrations. This has been seen in repeated comparisons between tomato and other indicator plant hosts by nucleic acid, serological, and light and electron microscopic studies.

Since beet pseudo yellows virus (BPYV) was first described in 1965 (13,34), at least six additional whitefly-transmitted RNA viruses have been reported including LIYV (15), LCV (17), TICV (16), ToCV (44), SPSVV (9,26,44), and CYSDV (7,14,21). Of these, LIYV, TICV, and SPSVV have been shown to contain a divided

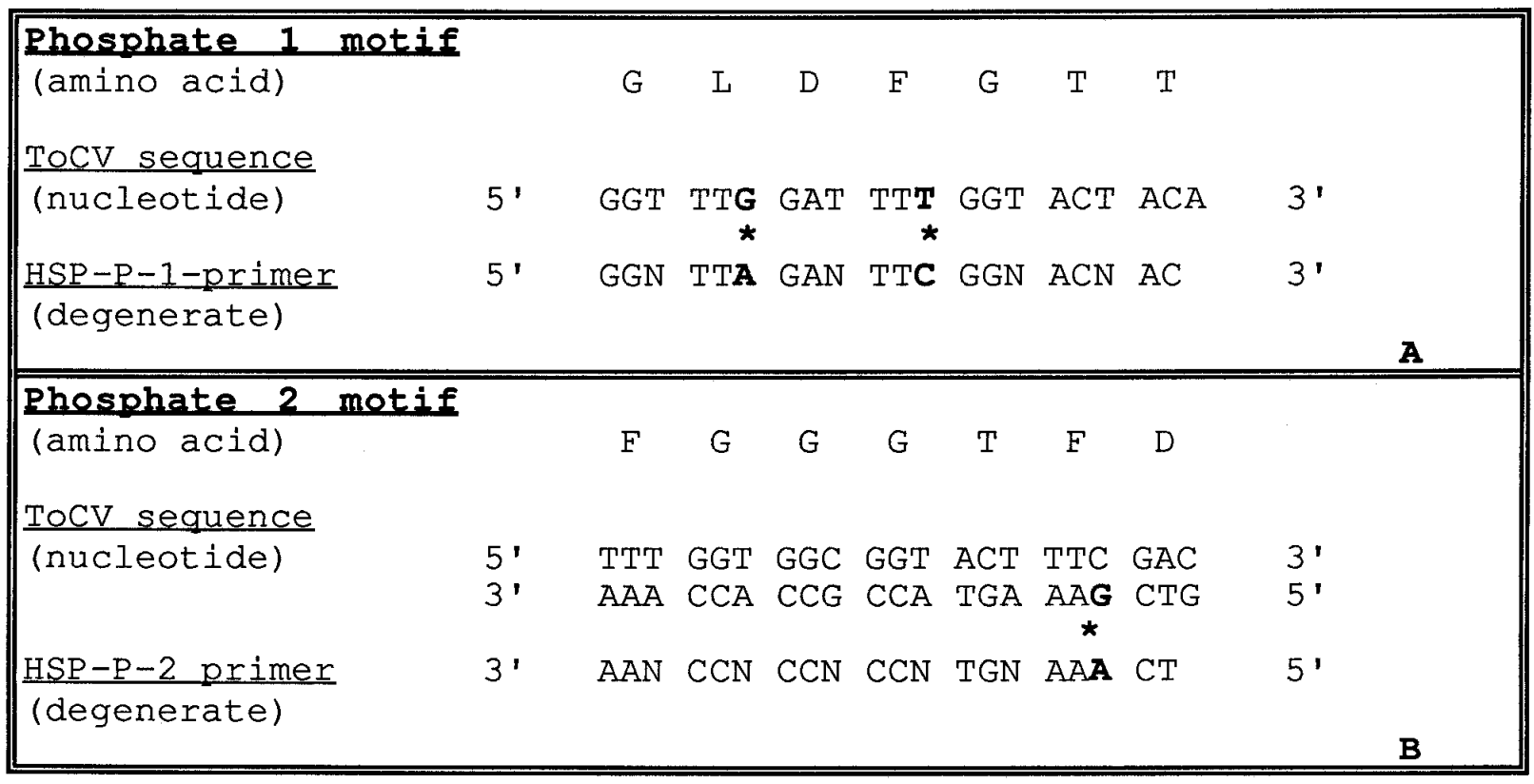

Fig. 6. Comparison of nucleotide sequence of tomato chlorosis virus (ToCV) in the region of $\mathbf{A}$, phosphate 1 and $\mathbf{B}$, phosphate 2 motifs of the heat shock protein 70 (HSP70) homolog with the degenerate primers designed to amplify whitefly closteroviruses in reverse transcriptase-polymerase chain reaction (40). The amino acid sequence for each motif is shown with the corresponding nucleotide sequences of ToCV and that of the degenerate primers. The nucleotide primer sequence is $\mathbf{A}$, of positive polarity and $\mathbf{B}$, the sequence complementary to the corresponding virus nucleotide sequence shown above. The differences between the ToCV nucleotide sequence and the primers are indicated by bold letters and an asterisk between the two corresponding nucleotides.

\begin{tabular}{|c|c|c|c|c|c|c|c|c|c|c|c|c|c|c|c|c|c|}
\hline & & & & + & & & & & & & & + & & + & & & \\
\hline $1 a$ & $\begin{array}{l}\mathrm{K} \\
\mathrm{AAG}\end{array}$ & $\begin{array}{l}\mathrm{V} \\
\text { GTT }\end{array}$ & $\begin{array}{l}\text { A } \\
G C T\end{array}$ & $\begin{array}{l}\text { D } \\
\text { GAT }\end{array}$ & $\begin{array}{l}\mathrm{H} \\
\mathrm{CAT}\end{array}$ & $\begin{array}{l}\text { I } \\
\text { ATC }\end{array}$ & $\begin{array}{l}I \\
A T A\end{array}$ & $\begin{array}{l}\mathrm{R} \\
\mathrm{AGG}\end{array}$ & $\begin{array}{l}\mathrm{E} \\
G A G\end{array}$ & $\begin{array}{l}\mathrm{C} \\
\mathrm{T} G \mathrm{~T}\end{array}$ & A & $\begin{array}{l}F \\
T T T\end{array}$ & $\begin{array}{l}K \\
A A A\end{array}$ & $\stackrel{Q}{C A G}$ & $\stackrel{Q}{C A G}$ & $\begin{array}{l}\mathrm{V} \\
\mathrm{GTT}\end{array}$ & $\stackrel{ }{*}$ \\
\hline $1 b$ & & & & & & & $\star$ & G & S & $\mathrm{V}$ & $\mathrm{H}$ & $\begin{array}{l}L \\
+\end{array}$ & $\mathrm{N}$ & $\begin{array}{l}S \\
+\end{array}$ & $R$ & $\begin{array}{l}F \\
+\end{array}$ & $\mathrm{N}$ \\
\hline
\end{tabular}

Fig. 7. The nucleotide and amino acid sequence (shown above the middle of each codon) of the putative +1 ribosomal frameshift region of tomato infectious chlorosis virus RNA 1 (presented as DNA). The overlapping reading frames of open reading frames 1a and 1b are shown on top and bottom, respectively. Stop codons are shown by asterisks, and amino acids identical to lettuce infectious yellows virus are shown by the corresponding + symbols. 
genome consisting of two ssRNAs $(25,28,29,46)$. Six of these viruses, LIYV, CYSDV, BPYV, LCV, SPSVV, and TICV, contain a gene encoding a heat shock protein 70 (HSP70) homolog that has been cloned and used for specific nucleic acid probes in dot blot hybridizations $(10,40)$. The sequences of these HSP70 clones exhibit significant similarity to the HSP70 homologs encoded by closteroviruses. Cytoplasmic vesicles and phloem-limited virus inclusions are also characteristic of closteroviruses and have been described for the whitefly-transmitted closteroviruses LIYV (23), LCV (35), SPSVV $(9,43)$ and TICV (46; G. C. Wisler, unpublished data).

Sequence analysis of the region spanning the $1 \mathrm{a} / 1 \mathrm{~b}$ ribosomal frameshift also showed similarities with members of the family Closteroviridae. The $(\mathrm{G} / \mathrm{C}) \mathrm{UU} \mathrm{U}^{* *}$ consensus (in which $* *$ refers to the last two bases in stop codons) is conserved within the LIYV, $\mathrm{BYV}$, and BYSV genomes (3) and in ToCV. In CTV, the rare arginine codon CGG is in place of a stop codon (28). ToCV is more like LIYV rather than like the monopartite closteroviruses in which a nine amino acid overlap with ORF 1a is observed upstream of the stop codon of ORF 1a. The slippery sequence of two overlapping codons, suggested as a mechanism for the $1 \mathrm{a} / 1 \mathrm{~b}$ frameshift of LIYV $(29,30)$, is not observed in the ToCV sequence.

LIYV is the type member and best-characterized bipartite closterovirus of the new genus Crinivirus $(29,30)$. Additional bipartite whitefly-transmitted viruses that share some characteristics with member of the genus Crinivirus have been described, and suggestions for changes in the taxonomy of the family have been made (12; G. P. Martelli, personal communication). ToCV belongs to this new bipartite closterovirus genus based on the divided genome, phloem-limited inclusions, and particle morphology (43), as well as the presence of the HSP70 homolog (40).

Currently, the distribution of TICV is distinct from ToCV. TICV has been found in several locations in California, North Carolina, and in Italy, whereas ToCV has been found in Florida, Louisiana, and Colorado to date. In addition, at least one new bipartite closterovirus that is distinct from either TICV or ToCV has been identified by dsRNA analysis, RT-PCR, dot blot hybridization, and Western blot analysis (G. C. Wisler and J. E. Duffus, unpublished data). Investigations are underway to further determine the distribution and movement of both TICV and ToCV and other related viruses, particularly in the rapidly expanding greenhousegrown tomato industry in which whitefly control can be difficult. The movement of tomato germ plasm and the intercropping of tomatoes with other greenhouse crops, particularly ornamentals, many of which are hosts of both TICV and ToCV, could contribute to the spread of both viruses and others that might be present.

\section{ACKNOWLEDGMENTS}

We thank R. C. Hochmuth and G. W Simone for providing plant samples from Florida; A. A. Cortez, J. L. Sears, and J. R. Knight for their excellent technical assistance; and Y.-p. Zhang for assistance with the electroporation of ToCV clones. We also thank A. V. Karasev for helpful discussions and assistance in analysis of sequence information.

\section{LITERATURE CITED}

1. Agranovsky, A. A. 1996. Principles of molecular organization, expression, and evolution of closteroviruses: Over the barriers. Adv. Virus Res. 47:119-158.

2. Altschul, S. I., Boguski, M. S., Gish, W., and Wootton, J. C. 1994. Issues in searching molecular sequence databases. Nat. Genet. 6:119-129.

3. Altschul, S. I., Gish, W., Miller, W., Myers, E. W., and Lipman, D. J. 1990. Basic local alignment search tool. J. Mol. Biol. 215:403-410.

4. Bellows, T. S., Perring, T. M., Gill, R. J., and Headrick, D. H. 1994. Description of a species of Bemisia [Homoptera, Aleyrodidae]. Ann. Entomol. Soc. Am. 87:195-206.

5. Bork, P., Sander, C., and Valencia, A. 1992. An ATPase domain common to prokaryotic cell cycle proteins, sugar kinases, actin, and hsp70 heat shock proteins. Proc. Natl. Acad. Sci. U.S.A. 89:7290-7294.
6. Brown, J. K., Frolich, D. R., and Rosell, R. D. 1995. The sweet potato or silverleaf whiteflies: Biotypes of Bemisia tabaci or a species complex? Annu. Rev. Entomol. 40:511-534.

7. Célix, A., López-Sesé, A., Almarza, N., Gómez-Guillamón, M. L., and Rodríguez-Cerezo, E. 1996. Characterization of cucurbit yellow stunting disorder virus, a Bemisia tabaci-transmitted closterovirus. Phytopathology 86:1370-1376.

8. Christie, R. G., and Edwardson, J. R. 1986. Light microscopic techniques for detection of plant virus inclusions. Plant Dis. 70:273-279.

9. Cohen, J., Franck, A., Vetten, H. J., Lesemann, D. E., and Loebenstein, G. 1992. Purification and properties of closterovirus-like particles associated with a whitefly-transmitted disease of sweet potato. Ann. Appl. Biol. 121:257-268.

10. Coutts, R. H. A., and Coffin, R. S. 1996. Beet pseudo-yellows virus is an authentic closterovirus. Virus Genes 13:179-181.

11. Devereux, J., Haeberli, P., and Smithies, O. 1984. A comprehensive set of sequence analysis programs for the VAX. Nucleic Acids Res. 12:387-395.

12. Dolja, V. V., Karasev, A. V., and Koonin, E. V. 1994. Molecular biology and evolution of closteroviruses: Sophisticated build-up of large RNA genomes. Annu. Rev. Phytopathol. 32:261-285.

13. Duffus, J. E. 1965. Beet pseudo-yellows virus, transmitted by the greenhouse whitefly (Trialeurodes vaporariorum). Phytopathology 55:450-453.

14. Duffus, J. E. 1995. Whitefly transmitted yellowing viruses of the cucurbitaceae. Cucurbitaceae 94:12-16.

15. Duffus, J. E., Larsen, R. C., and Liu, H.-Y. 1986. Lettuce infectious yellows virus-A new type of whitefly-transmitted virus. Phytopathology 76:97-100.

16. Duffus, J. E., Liu, H.-Y., and Wisler, G. C. 1994. Tomato infectious chlorosis virus-A new clostero-like virus transmitted by Trialeurodes vaporariorum. Eur. J. Plant Pathol. 102:219-226.

17. Duffus, J. E., Liu, H.-Y., Wisler, G. C., and Li, R. H. 1996. Lettuce chlorosis virus-A new whitefly-transmitted closterovirus. Eur. J. Plant Pathol. 102:591-596.

18. Duffus, J. E., Wisler, G. C., Liu, H.-Y., Li, R. H., Simone, G. W., and Hochmuth, R. C. 1997. Whitefly-transmitted tomato leaf yellowing viruses-A disease complex. Pages 67-69 in: Proc. Annu. Tomato Dis. Workshop, 12th. Ohio State University, ORADC, Columbus.

19. Hadidi, A., and Yang, X. 1990. Detection of pome fruit viroids by enzymatic cDNA amplification. J. Virol. Methods 30:261-270.

20. Halk, E. L. 1986. Serotyping plant viruses with monoclonal antibodies. Pages 766-780 in: Methods in Enzymology. A. Weissbach and $\mathrm{H}$. Weissbach, eds. Academic Press, New York.

21. Hassan, A. A., and Duffus, J. E. 1991. A review of a yellowing and stunting disorder of cucurbits in the United Arab Emirates. Emir. J. Agric. Sci. 2:1-16.

22. Hoefert, L. L., McCreight, J. D., and Christie, R. D. 1992. Microwave enhanced staining for plant virus inclusions. Biotechnol. Histochem. 67:40-44.

23. Hoefert, L. L., Pinto, R. L., and Fail, G. L. 1988. Ultrastructural effects of lettuce infectious yellows virus in Lactuca sativa L. J. Ultrastruct. Mol. Struct. Res. 98:243-253.

24. Holmes, D. S., and Quigley, M. 1981. A rapid boiling method for the preparation of bacterial plasmids. Anal. Biochem. 114:193.

25. Hoyer, U., Jelkmann, W., Maiss, E., and Vetten, H. J. 1996. Sweet potato sunken vein virus: Another bipartite closterovirus transmitted by $B e$ misia tabaci Genn. Page 89 in: Proc. Int. Congr. Virol., 10th. Int. Congr. Virol., Jerusalem, Israel.

26. Hoyer, U., Maiss, E., Jelkmann, W., Lesemann, D.-E., and Vetten, H. J. 1996. Identification of the coat protein gene of a sweet potato sunken vein closterovirus isolate from Kenya and evidence for a serological relationship among geographically diverse closterovirus isolates from sweet potato. Phytopathology 86:744-750.

27. Karasev, A. V., Boyko, V. P., Gowda, S., Nikolaeva, O. V., Hilf, M. E., Koonin, E. V., Niblett, C. L., Cline, K., Gumpf, D. J., Garnsey, S. M., Lewandowski, D. L., and Dawson, W. O. 1995. Complete sequence of the citrus tristeza virus RNA genome. Virology 208:511-520.

28. Karasev, A. V., Nikolaeva, O. V., Mushegian, A. R., Lee, R. F., and Dawson, W. O. 1996. Organization of the 3'-terminal half of beet yellow stunt virus genome and implications for the evolution of closteroviruses. Virology 221:199-207.

29. Klaassen, V. A., Boeshore, M., Dolja, V. V., and Falk, B. W. 1994. Partial characterization of the lettuce infectious yellows virus genomic RNAs, identification of the coat protein gene and comparison of its amino acid sequence with those of other filamentous RNA plant viruses. J. Gen. Virol. 75:1525-1533.

30. Klaassen, V. A., Boeshore, M. L., Koonin, E. V., Tian, T., and Falk, B. W. 1995. Genome structure and phylogenetic analysis of lettuce infectious yellows virus, a whitefly-transmitted, bipartite closterovirus. Virology 208:99-110.

31. Lee, S., and Rasheed, S. 1990. A simple procedure for maximum yield of 
high-quality plasmid DNA. BioTechniques 9:676-679.

32. Li, R. H., Wisler, G. C., Liu, H.-Y., and Duffus, J. E. 1998. Comparison of diagnostic techniques for detecting tomato infectious chlorosis virus. Plant Dis. 82:84-88.

33. Liu, H.-Y., Cohen, S., and Duffus, J. E. 1992. The use of isozyme patterns to distinguish sweetpotato whitefly (Bemisia tabaci) biotypes. Phytoparasitica 20:187-194.

34. Liu, H.-Y., and Duffus, J. E. 1990. Beet pseudo-yellows virus: Purification and serology. Phytopathology 80:866-869.

35. Petersen, M. A., Wisler, G. C., Purcifull, D. E., and Duffus, J. E. 1996. Cytopathology of infections caused by the whitefly-transmitted lettuce chlorosis closterovirus. (Abstr.) Phytopathology 86:S71.

36. Pinto, R. L., Hoefert, L. L., and Fail, G. L. 1988. Plasmalemma deposits in tissues infected with lettuce infectious yellows. J. Ultrastruct. Mol. Struct. Res. 100:245-254.

37. Reynolds, E. 1963. The use of lead citrate at high $\mathrm{pH}$ as an electronopaque stain in electron microscopy. J. Cell Biol. 17:208-212.

38. Sambrook, J., Fritsch, E. F., and Maniatis, T. 1989. Molecular Cloning: A Laboratory Manual. Cold Spring Harbor Laboratory, Cold Spring Harbor, NY.

39. Simone, G. W., Hochmuth, R. C., Wisler, G. C., Duffus, J. E., Liu, H.-Y., and $\mathrm{Li}, \mathrm{R}$. H. 1996. A new whitefly-vectored closterovirus of tomato in Florida. Pages 71-74 in: Tomato Inst. Proc. C. S. Vavrina, ed. Hart Science Department, IFAS, University of Florida, Gainesville.
40. Tian, T., Klaassen, V. A., Soong, J., Wisler, G., Duffus, J. E., and Falk, B. W. 1996. Generation of cDNAs specific to lettuce infectious yellows closterovirus and other whitefly-transmitted viruses by RT-PCR and degenerate oligonucleotide primers corresponding to the closterovirus gene encoding the heat shock protein 70 homolog. Phytopathology 86:1167-1173.

41. Towbin, H., Staehelin, T., and Gordon, J. 1979. Electrophoretic transfer of proteins from polyacrylamide gels to nitrocellulose sheets: Procedure and some applications. Proc. Natl. Acad. Sci. U.S.A. 76:4350-4354.

42. Valverde, R. A., Nameth, S. T., and Jordan, R. L. 1990. Analysis of double-stranded RNA for plant virus diagnosis. Plant Dis. 74:255-258.

43. Winter, S., Purac, A., Leggett, F., Frison, E. A., Rossel, H. W., and Hamilton, R. I. 1992. Partial characterization and molecular cloning of a closterovirus from sweet potato infected with the sweet potato virus disease complex from Nigeria. Phytopathology 82:869-875.

44. Wisler, G. C., Duffus, J. E., Liu, H.-Y., Li, R. H., Simone, G. W., and Hochmuth, R. C. 1996. A new, whitefly-transmitted virus infecting tomato from Florida. (Abstr.) Phytopathology 86:S71-S72.

45. Wisler, G. C., Li, R. H., Liu, H.-Y., and Duffus, J. E. 1997. Partial molecular and cytological analyses of tomato chlorosis virus. (Abstr.) Phytopathology 87:S104.

46. Wisler, G. C., Liu, H.-Y., Klaassen, V. A., Duffus, J. E., and Falk, B. W. 1996. Tomato infectious chlorosis virus has a bipartite genome and induces phloem-limited inclusions characteristic of the closteroviruses. Phytopathology 86:622-626. 